\title{
Construction of Reading Meaning for Application User Wattpad Indonesia
}

\author{
https://doi.org/10.25008/jkiski.v5i2.414 \\ Genny Gustina Sari ${ }^{*}$, Welly Wirman ${ }^{2}$, Vindriana Adios ${ }^{3}$ \\ 1,2,3 Department of Communication Study - Universitas Riau \\ Jl. H.R. Subrantas Km. 12,5 Simpang Baru, Pekanbaru 28293 - Indonesia \\ *Corresponding author: genny.gustina@1ecturer.unri.ac.id
}

Submitted: September 30, 2020, Revised: November 27, 2020, Accepted: December 30, 2020

Accredited by Kemristekdikti No. 28/E/KPT/2019

\begin{abstract}
Wattpad is an application for reading mobile to help people read and share their story by reading. This study aims to determine how the user of Wattpad makes sense about reading activity and how is the meaning of Wattpad for them to use Wattpad as media. This research uses qualitative descriptive methods with a phenomenology-virtual approach. The subject of the research consisted of three Wattpad ambassadors in Indonesia selected by the purposive technique. The results of this research are the meaning of reading by the user, that is (1) Habit, this explains reading as an activity they have started since their childhood until now and that becomes activity as habitually for the informants. (2) Necessary, that means the informants need to read every time (3) Addictive, that means addict to read and find some books that they like. Meanwhile, the meaning of Wattpad as media, find two means there are (1) Second After Books, that means Wattpad is the only alternative media for reading. (2) Jumping Stone, that means Wattpad is the platform to meet the user masterpiece to the readers and make them a real writer.
\end{abstract}

Keywords: Meaning; reading; Wattpad; construction; phenomenology virtual

\section{Introduction}

Communication technology has developed very rapidly in the past decade. Various daily activities seemed to experience a revolution since the presence of new media. David Holmes, elaborates more about the achievement of this era with The Second Media Age, which is not just about the evolution of communication media, yet it's regarding a level of communication integration of assorted communication platform. One of the human activities that contributes to digitizing is the reading activity. According to UNESCO. in 2012 Indonesia has a low reading interest which is only $0.001 \%$ disparate from Singapore which can hook $54.4 \%$. This is supported by research conducted by Olynda Ade Arisma (Richard Stevens, Stevens, \& Bell, 2012) citing Kusmana (2009), based on the results of the research Program for International Student Assessment, which is known Our students' reading interest is low. While analyzing with countries in East Asia, Indonesian students are among the lowest of 42 countries surveyed, Indonesian students were ranked 39th, slightly above Albania and Peru. The ability of our students is still beneath Thai students in 32nd place.

The reason for the depressed reading interest in Indonesia is caused by many things, such as most Indonesian people are not familiar with books early on, parents prefer to teach children to watch TV or play a gadget than to accompany them reading a book. Thus, the majority of Indonesian people are more interested in the source of information that is heard and see the display moves. Meanwhile, for Indonesian people, the book is not a necessity whereas gadgets are the primary requirement currently, especially among students. Indonesian students reportedly spent 10 hours on the internet per day. They use the internet for various daily 
activities, starting from activities to support the learning process such as googling and others, to engage various hobbies such as sports, photography, music, up to read books with applications.

When discussing about reading activities, indeed the development is also not separated from the impact of technological developments among the print media. Starting from the invention history of printing by Guttenberg (1439), then three computer-grade evolutions have been taking effect on the book industry: (1) digitization of Google's printed books; (2) Kindle impact on receipt of ebooks; (3) publication of books on request (Straubhaar, LaRose, \& Davenport, 2012).

The transformation of the conventional book industry into digital seems to make conventional books increasingly abandoned due to the electronic book (e-book) that has engaged the reader's need for books. In addition, for practical and economical reason, it does not need to think of heavy book weight, unworry about the risk of damaged books such as torn or wet and it can also be downloaded easily even some are free. A wide selection of apps is present for those who love to read. From the start newspapers, comics, magazines, novels, and even scriptures can be read. The survey conducted by one of the sites selling and buying books online togamas.com of 1,000 books sold each month, 700800 is a Genre of fiction ie novel. Most of the market is teenagers. The fiction genre is the type of book that attract most book lovers in Indonesia.

The presence of various applications is helpful to read virtual books with the fiction genre popping up. Wattpad is one of the applications that allows users to read, write, and share stories in the form of novels, poems, or short stories with various types of genres. Wattpad is one of the five best 2015 heavy-reading apps (Syaharani \& Mahadian, 2017) and one of 5 apps that allow users to be readers and writers in this Wattpad app. Wattpad has a feature where authors and readers can interact each other by sending direct messages or writing on the wall of other users. Wattpad also allows readers to comment and vote with the same function as like for writers in every part or even paragraphs. Wattpad also features followers and following like other social media. Ease of interaction between users provides a different reading experience on Wattpad. Each user has the opportunity to upload his literary work and be enjoyed by other users. So, not a few of the users finally gave birth to works of professional literacy published conventionally.
As digital comic book consumption continues to rise in popularity, the comic book community appears conflicted over the effects of digital scans have on the meaning of collecting and reading comic books. Historically, comic ownership served as the locus of comic fan social capital; will digital scans hold the same cultural capital as printed books? And does post-purchased digital scan dissemination primarily hurt copyright holders through lost sales, or does it help through social promotion? (J.R. Stevens \& Bell, 2012).

The author is interested in discussing more Wattpad because it not only converts from conventional media such as books to digital, yet Wattpad allows users to write digitally and permit to upload their work in Wattpad printed into conventional books anymore. Wattpad read activity enables the sale of books with the system (pre-order). This makes the Wattpad seem to have its uniqueness compared to other read applications. Book lovers not only read passively but also produce works. The flexibility of users to interact with each other makes the work of authors on the Wattpad account increasingly tested its quality. Thus, the authors want to engage more about the user's process of interpreting Wattpad as a medium and interpretation of the user for construing activities to read the book itself, both of conventionally and digitally even able to combine it.

\section{Theoretical Framewok}

Phenomenology is a qualitative study approach rooted in philosophy and psychology, and it focuses on the human experience. The phenomenological study uses life experiences as a tool to advance discern the social, cultural, political, or historical context in which the experience occurred. The theoretical assumption in the phenomenological approach mentions the individual actively interprets their experiences and tries to understand them by personal experience. The phenomenology conceives a real experience as a core data of reality. The substance point is that the individual knows what they experience.

Stanley Deetz in (W Stephen \& A Foss, 2011) summarizes three basic principles of phenomenology, namely: (1) Knowledge is found directly in the conscious experience that we will know the world when we are in contact with it. (2) The meaning of an object consists of the power of an object in one's life. In other hand, how you relate to things determines their meaning for you. (3) Language is the vehicle of meaning. We 
experience the world through language we used to define and express it.

Schutz and the phenomenological specialist assume that the main burden of the phenomenon's analysis is to reconstruct the "real" world of human life in a form which they experience. The realities of that world are intersubjective in that members of society share basic perceptions of the world they are internalized through socialization and allow them to have interaction or communication (Mulyana, 2010). Thus, the phenomenological emphasizes real experiences as the subject of reality. In phenomenology, everything is described as it is.

In this study, the authors conducted studies through internet media and virtual interaction. In previous research, the phenomenological has not been further expounded on the research of the phenomenology using virtual media, yet the authors still adopt the phenomenology since it is appropriate to view from that aspect. However, since the study is composed of observation and interviews through virtual media, the authors adopted this research in a virtual phenomenology approach.

This perspective tries to understand reality from the subject's point of view. Understanding Wattpad users present for digital or conventional reading and explains Wattpad as a medium in the form of the informant experienced. The study uses the symbolic interaction theory. Ralph LaRossa and Donald C. Reitzes (In west, Turner. 2009:98) say that three major themes could be studied by symbolic interactions: (1) the importance of meaning for human behavior (2) the importance of the concept of self (3) the relationship between the individual and society.

The affairs between the individual and society. The above theme is supported by Blumer's thoughts that administer some basic assumptions related to symbolic interaction theory. West and Turner (west Richard, \& Turner, 2009) summarized the three assumptions: (1) Humans act towards other humans based on the meaning of their giving to other. This assumption describes behavior as a set of thoughts. These behaviors are done consciously, depending on stimulation and response received.

The meaning we give to a symbol is a product of social interaction and represents a human agreement to apply a particular meaning to a particular symbol as well. This means that a symbol has the same meaning when there's an agreement to interpret the symbol. (2) Meaning is created in human interaction. According to Mead, the meaning would exist if people had the same interpretation of symbols of exchangin in interactions.

Blumer defines meaning into three, namely: (1) meaning is something that is intrinsic to an object, (2) meaning is something "brought to an object by someone for whom the subjects are meaningful" in other words, meaning is in people and is not in objects, (3) meaning is "a social product" or "a creation formed by a definition of human activity when they interact". (3) Meaning is modified by the interpretive process. Blumer said that the interpretive process has two steps, namely: (1) the actor determines objects that have meaning (2) the actor is involved in selecting, checking, and transforming or changing meanings in the context in which they are located.

The essential point of symbolic interaction is an activity characterized by humans, particularly communication or exchange of symbols that are given meaning. Symbolic interaction seeks to understand human behavior from the point of view of the subject. Human behavior is seen as a process that allows humans to shape and regulate their behavior by considering the expectations of others with whom they interact (Mulyana. 2010: 68-70). The meaning of something can constantly change. It is influenced by a change of time and environment that will also change a person's value system, beliefs, and attitudes toward something. As stated by Joseph de Vito (in Wirman. 2012: 49) "Look for meaning in people, not in words." Meanings change yet words are relatively static, and share meaning, not only words through communication". Changing words are hard, and your share sense, not only words through communication." While mulyana (in Wirman, 2012:49) also explains that words do not have meaning, however it is the person that gives meaning.

Meaning is not attached to words, nevertheless words arouse meaning in people's minds. Moreover, the meaning we give to the same word can be different depending on place and time. Meaning arises from the special relationship among words (as verbal symbols) and humans. Odgens and Richard (in Wirman, 2012: 49) explain the bounding between the mind, the symbols and references diagrammatically in a triangle of meaning as shown in the following picture. 


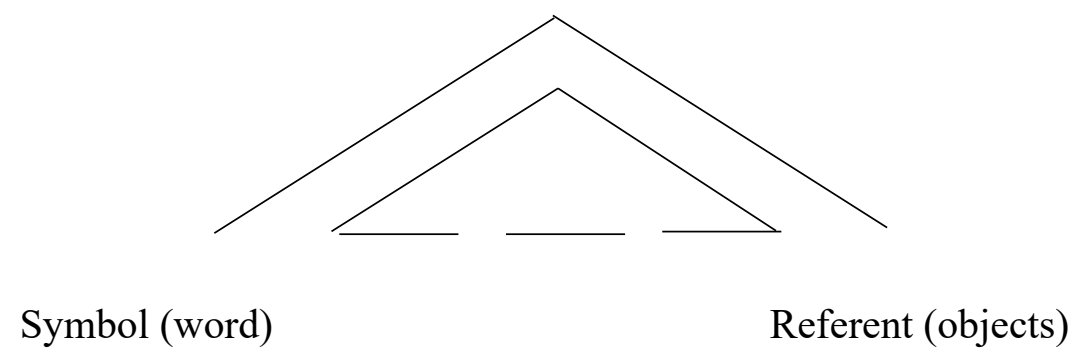

Figure 1. Triangle Meaning Thought or Reference (Person)

Source: Bert E. Bradley (Wirman Welly, 2012)

The picture explains that meaning is the relationship between the three components of one's thought or reference, symbol or word, and reference or object. Meaning arises from the relationship between people's thoughts and symbols or between people's thoughts and referrals.

Meanwhile, amid the referral and the symbol, there is no direct natural relationship. It means that a word doesn't perpetually represent an object. Cultural differences, value systems, beliefs often influence the word used to refer to objects.

\section{Material and Methodology}

This research uses a qualitative method with a virtual phenomenology approach and presentation of the descriptive analysis presented in the form of description according to language, way of the view of research subject concerning the problem under study which is also the data. This research is conducted using virtual media intermediary so that the phenomenology approach made by the writer is virtual, that is the main instrument approach is interview and observation. However, both processes done by writers use intermediary of virtual media so that writers call this research using the qualitative method with virtual phenomenology.

Qualitative research shows research on community life, history, behavior, or kinship relationship (Jaenal \& Syamsir, 2006). According to Denzin and Lincoln (Moleong, 2005), qualitative research is a study using a natural setting, with the intent to interpret the phenomenon that occurs and is done by involving various existing methods. This means that research describes something as it is following actuality that happened. Thus, to get an objective conclusion, researchers try to understand the symptoms by interpreting the various problems that occur in every situation.

The phenomenological approach is used to answer the question of the phenomenon that occurs by paying attention to the perception and meaning of a person in understanding the experience they feel to be interpreted. (Syaharani \& Mahadian, 2017) state that there is no objective reality separate from one's person.

There is only experience and meaning that will have two implications, namely how one interprets the world and perceives what others feel through direct participation.

(1) The characteristics of phenomenological research areas revealed by Kuswarno are as follows: Focus on something that appears, return to the true (essence), get out of the routine and out of what is believed to be the truth and habits of everyday life;

(2) Phenomenology is interested in the whole, by observing entities from different perspectives and perspectives to the point of view of the essence of experience or phenomena to be observed;

(3) Phenomenology seeks the meaning and essence of appearance, with intuition and reflection in conscious action through experience. This meaning leads ultimately to the ultimate idea, concept, judgment, and understanding;

(4) Phenomenology describes the experience, not explaining or analyzing it. A description of phenomenology will be very close to the naturalness (texture, quality, and supporting properties) of something. Thus, the description will preserve the phenomenon as it is, and accentuate the nature and meaning behind it. Besides, the description also makes the phenomenon of "life" in sound and complete terms. In other words, the same "life" is between that which appears in consciousness and that seen by the five senses;

(5) Phenomenology is rooted in questions directly related to the meaning of the observed phenomenon. Thus, phenomenological research will be very close to the observed phenomenon. The analogy of the researcher is one of the puzzle parts of a story or biography;

(6) Integration of subject and object. The perception of the researcher will be equal or equal to what he/she hears. The experience of action will make the object a subject, and the subject becomes 
the object of an investigation conducted within an intersubjective framework, reality is one part of the process as a whole;

(7) The data obtained (through thought, intuition, reflection, and judgment) are the main shreds of evidence in scientific knowledge (Engkus, 2009) This study attempts to describe the real state of constructing the meaning of reading for Wattpad users.

Researchers try to find out how the Wattpad user gets the value of the reading activity and how the research subject understands application to read Wattpad as media. The process of data retrieval is done by observation, documentation, and in-depth interviews with research subjects using virtual media so that the authors state that this research uses qualitative research method of virtual phenomenology approach.

\section{Results and Discussion}

Identifying the perspective of symbolic interaction, Mead (Mulyana, 2010) assumes that meaning is the product of social interaction. Hence, the meaning is not attached to the object but is negotiable through the use of language. Those having an early habit of reading and surviving until currently certainly have a social environment that supports these activities and experience interaction with people around the environment about reading material they read. They further negotiate the symbol with the meaning of reading through social interaction that they do continuously to adulthood. Thus, they interpret the activity of reading as a custom.

The meaning of reading that is interpreted by the next Wattpad user is the meaning considered necessary. This meaning appears to be found on Wattpad users who interpret their reading activity as a need that must be met. Need, according to
Indonesia Big Dictionary (Kamus Besar Bahasa Indonesia/KBBI), is everything that must be met. Meanwhile, according to Maslow, needs are divided into various levels, which at the top level we recognize the term needs self-actualization, namely the need to do something that seems to be passion of someone. Just as a musician has to play music, an artist has to paint and so does a writer have to write and read. Reading is part of the need for self-actualization for those who love reading. Without reading their lives will be disturbed and felt incomplete.

This meaningful significance can also be seen from the behavior shown by the Wattpad users themselves. One informant confessed that he would return home if his access to Wattpad (mobile) was left on a long journey and it would be disturbed if it did not meet his need to read. Or he is willing to buy the same book when the book he had prepared was lost on the way. This proves that the informant interpreted reading as a necessity or also called necessary.

The meaning of other reading, according to the informant, is Addictive. In this sense, the authors found that informants made reading as an activity that made them opium. Based on KBBI opiate has the meaning as an upsurge of passion until forget other things. They argue that reading activities that have become their habit since childhood and are ongoing, then become necessities, will then lead them to the meaning of reading as an opiate they will naturally fulfill. Addictive here is their dependence on a particular book genre that makes them become loyal to a work with a similar genre or even by a particular author. Then their addiction to the genre leads them to the decision to collect certain types of books and to sacrifice something to satisfy their addiction to a particular book or author.

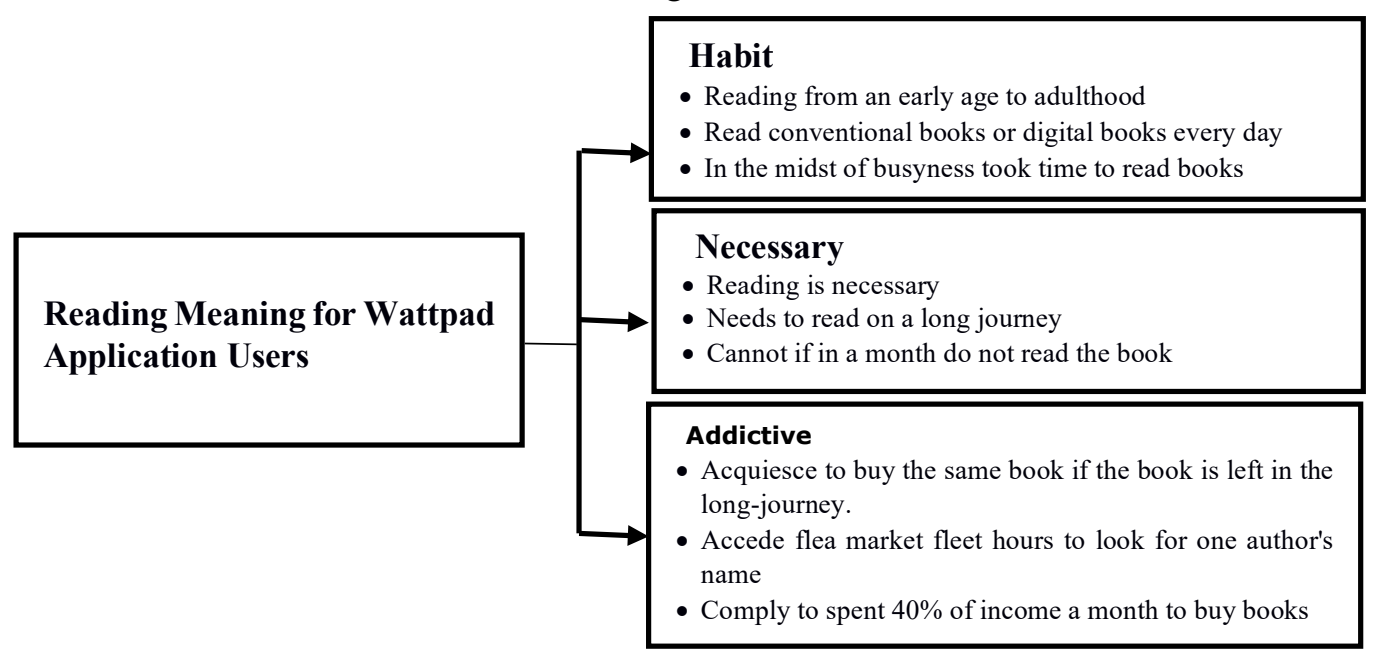

Figure 2. Reading Meaning for Wattpad Application 


\section{Meaning Wattpad as Media}

One of the implementation of media development is the conventional book digitization. Wattpad is part of the many applications that provide digital reading. Wattpad has a feature to allow users to not only read, but also to have the opportunity to become a writer and his work enjoyed by all users in the world. Various conveniences in declaring Wattpad as a medium was able to reconcile the work of the author with the readers so that he can become a commercial writer. However, these features do not need to eliminate the conventional book position in the hearts of its users, since the reality in the field that the author finds is the number of writers debuting on the Wattpad that sells his work in the form of conventional books and still sells in the market. The buyers are mostly from their loyal readers in digital media. This means that conventional books still do not lose prestige in the eyes of readers.

As follows the one meaning of Wattpad as a medium is second choice after books, the authors found that users use Wattpad as an alternative media to read after the book. The convenience offered by Wattpad does not cause users to leave conventional books just like that. As the informants point out, they feel they need to buy conventional books for reading. All three informants acknowledged having done self-publishing in Wattpad and doing open order promotion to their users with the help of Wattpad media, and the result of their work was accepted conventionally. Even one of the informants admitted that he dared to pull out of the publication and chose to display his work independently because he felt he had a fixed customer and the turnover earned from independent writing was greater than issuing major (using the services of the publisher). Hence, the authors conclude that informants interpreted Wattpad as Jumping Stone or stepping stone that eventually led them to become a professional writer as he is now. Based on the authors' findings on the meaning of Wattpad as a medium, the authors summarize it in a model as follows:

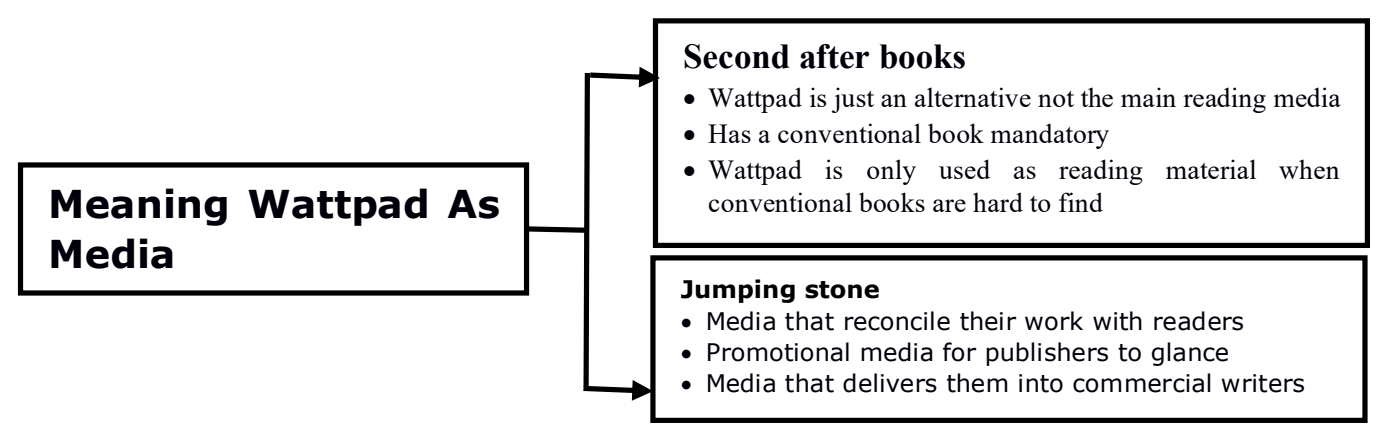

Figure 3. Meaning Wattpad as Media

\section{Conclusion}

Based on the discussion that the author did on the study of the meaning of reading constructions for Wattpad users, then the conclusion is: (1) The meaning of reading that is interpreted by Wattpad users is reading as habit i.e. users interpret reading as a habit in their life. Their familiarity with books and reading activities from an early age and lasting on an ongoing basis makes them read as a habit in their lives.

Furthermore, reading as necessary that informants interpret reading as a need that they must meet, when the need is not met it will disturb their peace of life. Thusly, they will strive for these needs being met. Furthermore, reading as addictive is to interpret reading as an activity that makes them opium. The addictive referred to herein can mean a variety of opium in certain genres, certain authors, until the particular reading media.
The meaning of Wattpad as a medium interpreted by the Wattpad user is divided into two, namely second book, for Wattpad users, conventional book cannot be replaced completely by digital book, the presence of digital reading applications only comes second after the conventional book. While the next meaning is jumping stone, is the meaning for the informants who claim that Wattpad is a bridge to bring their creation with readers. For them the Wattpad app really assisted them in introducing their work to all over the world. Hence, the opportunity is to be a work that can be valuable commercially for the author. The features presented by Wattpad support the progress of its users to become more mature writers and more critical readers because of the free interaction between fellow users take place in this Wattpad read app. 


\section{References}

Engkus, K. (2009). Fenomenologi. Bandung: Widya Padjajaran.

Jaenal, A., \& Syamsir, S. (2006). Metode Penelitian Sosial. Jakarta: UIN Jakarta Press.

Moleong, L.J., (2005). Metode Penelitian Kualitatif Edisi Revisi. Bandung: Rosdakarya.

Mulyana, D. (2010). Metodologi Penelitian Kualitatif: Paradigma Baru Ilmu Komunikasi dan Ilmu Sosial Lainnya. Bandung: Remaja Rosdakarya.

Stevens, J. R., \& Bell, C. E. (2012). Do Fans Own Digital Comic Books? Examining the Copyright and Intellectual Property Attitudes of Comic Book Fans. 6, 751-772.

Straubhaar, J., LaRose, R., \& Davenport, L.
(2012). Media Now 7th understanding Media, Culture, and Technology. New York: Wadsworth.

Syaharani, N., \& Mahadian, A. B. (2017). Di Wattpad. Jurnal Komunikasi Global, 6(1), 120.

W Stephen, L., \&, \& A Foss, K. (2011). Teori Komunikasi; Theories of Human Communication. Jakarta: Salemba Humanika.

West Richard, \&, \& Turner, L. (2009). Pengantar Teori Komunikasi: Analisis dan Aplikasi. Jakarta: Salemba Humanika.

Wirman Welly. (2012). Pengalaman Komunikasi dan Konsep Diri Perempuan Gemuk. Journal of Dialectics IJAD. Bandung: Pascasarjana Unpad, 2(1). 